\title{
Distinct patterns of angiogenic factor expression as a predictive factor of response to chemotherapy in stage IIIA non-small-cell lung cancer patients
}

\author{
NIKOLAOS KOUFOS $^{1 *}$, JOHN SYRIOS $^{2 *}$, DESPINA MICHAILIDOU ${ }^{1}$, \\ IOANNIS D. XYNOS ${ }^{3}$, ANDREAS LAZARIS ${ }^{4}$, NICOLAOS KAVANTZAS ${ }^{4}$, PERICLIS TOMOS ${ }^{5}$, \\ STAMATIS KAKARIS $^{6}$, CHRISTOS KOSMAS $^{7}$ and NIKOLAS TSAVARIS ${ }^{1}$
}

\begin{abstract}
${ }^{1}$ Oncology Unit, Department of Pathophysiology, Laiko General Hospital, School of Medicine, National and Kapodistrian University of Athens, 11527 Athens; ${ }^{2}$ 2nd Department of Medical Oncology, 'St. Savvas' Cancer Hospital, 11522 Athens, Greece; ${ }^{3}$ Imperial Clinical Trials Unit-Cancer, Department of Surgery and Cancer, Charing Cross Hospital, Imperial College, London W6 8RF, UK; ${ }^{4} 1$ st Department of Pathology and ${ }^{5}$ 2nd Department of Propedeutic Surgery,

Laiko General Hospital, School of Medicine, National and Kapodistrian University of Athens, 11527 Athens;

${ }^{6} 1$ st Department of Thoracic Surgery, 'Sotiria' General Hospital of Chest Diseases, 11527 Athens; ${ }^{7}$ 2nd Division of Medical Oncology, Department of Medicine, Metaxa Cancer Hospital, 18537 Piraeus, Greece
\end{abstract}

Received November 9, 2015; Accepted February 3, 2016

DOI: $10.3892 / \mathrm{mco} .2016 .966$

\begin{abstract}
The expression of various angiogenic factors was assessed in tumour samples of patients with stage III non-small-cell lung cancer (NSCLC) and further evaluated in terms of response to induction paclitaxel-ifosfamide-cisplatin chemotherapy. Freshly isolated lung tumour specimens obtained by bronchoscopy from 70 stage IIIA NSCLC chemotherapy-naïve patients were sampled and analysed for vascular endothelial growth factor receptor (VEGFR)-1, VEGFR-2 and VEGFR-3. Microvessel density was assessed through evaluating the angiogenic markers CD34 and CD105. Immunostaining scores were calculated by multiplying the percentage of labeled cells by the intensity of staining for each examined parameter. The overall mean immunostaining score value from all NSCLC samples was 7.83, 5.56 and 15.86 for VEGFR-1, VEGFR-2 and VEGFR-3, respectively. The overall mean value of the endothelial antigen CD34 was 16.29 , whereas the expression of the CD105 antigen in endothelial cells yielded a multivariate distribution. Patients who responded to chemotherapy expressed significantly higher VEGFR-1 and VEGFR-3
\end{abstract}

Correspondence to: Dr Nikolaos Koufos, Oncology Unit, Department of Pathophysiology, Laiko General Hospital, School of Medicine, National and Kapodistrian University of Athens, 17 Agiou Thoma Street, 11527 Athens, Greece

E-mail:koufos_nikos@hotmail.com

*Contributed equally

Key words: angiogenesis, chemotherapy, cytokines, microvessel density, non-small-cell lung cancer, predictive factors, prognostic factors, vascular endothelial growth factor receptors mean values compared with non-responders $(\mathrm{P}<0.001)$. No significant difference was noted in VEGFR-2 mean values between these two groups $(\mathrm{P}=0.06)$. The $\mathrm{CD} 34$ mean value was significantly higher in responders $(\mathrm{P}<0.001)$, whereas there was no significant difference in CD105 expression between the two groups $(\mathrm{P}=0.07)$. Angiogenic marker expression proved to be a potential predictive factor of response to chemotherapy in stage III NSCLC. which merits further investigation.

\section{Introduction}

Tumour angiogenesis is a process essential for cancer cell proliferation, invasion and metastasis (1). The balance between pro- and anti-angiogenic factors, including growth factors, cytokines and chemokines, which is responsible for normal angiogenesis, is disrupted during tumourigenesis $(2,3)$.

Vascular endothelial growth factor (VEGF) is a critical pro-angiogenic protein that drives tumour angiogenesis. The biological functions of VEGF are mediated upon binding to type III receptor tyrosine kinases, VEGF receptor (VEGFR)-1, VEGFR-2 and VEGFR-3 (4-7).

VEGFR-1 plays an important role in tumour progression and dissemination, and enhances tumour metastasis in the lung via induction of matrix metalloproteinase 9 (8). The binding of VEGF to VEGFR-2 activates multiple signalling pathways, resulting in upregulation of endothelial cell proliferation, migration and survival and an increase in vascular permeability. Expression of VEGFR-2 in combination with VEGFR-3 is significantly upregulated in the tumour vascular endothelium of the most common human solid tumours. VEGFR-3 is largely confined to the lymphatic endothelium in adult tissues, but its expression also plays a fundamental role in the tumour microenvironment by promoting the sprouting of new lymphatic vessels from pre-existing ones $(7,9,10)$. 
Microvessel density (MVD), as determined by the expression of the endothelial antigens CD34 and CD105, is a direct neoangiogenesis marker and an important prognostic indicator in NSCLC. MVD has been shown to be correlated with the concentration and expression of VEGF; it is also associated with enzymes involved in the early stages of angiogenesis, tumour growth and occurrence of distant metastasis (11-13).

There is plentiful literature regarding the association of angiogenic factors with disease prognosis $(4,14-20)$; however, only a few studies evaluate the role of such factors in predicting response to chemotherapy (21-25).

Platinum-based doublet chemotherapy is considered the current standard of care for patients with stage III NSCLC; however, a number of patients in our institution were historically treated with the combination of paclitaxel-ifosfamide-cisplatin (TIP), based on earlier study reports (26-28). In the present study, the expression of VEGFR-1, VEGFR-2, VEGFR-3, and the endothelial markers CD34 and CD105, was assessed in tumour samples of patients with stage III NSCLC; the respective parameters were further analyzed retrospectively in relation to response to induction TIP chemotherapy.

\section{Patients and methods}

Study design. A total of 70 patients with stage IIIA NSCLC treated with induction TIP chemotherapy at our institution between 1998 and 2008 were retrospectively analysed. The patients were staged according to the American Joint Committee on Cancer/Union for International Cancer Control tumour-node-metastasis staging system (6th edition) (29) and classified into two equal-sized groups $(n=35)$ based on response to chemotherapy (responders vs. non-responders). The responders and non-responders were subsequently offered surgery and radiotherapy, respectively. The groups were matched by pre-treatment patient and tumour characteristics (Table I).

The study protocol was approved by the Ethics Committee of Laiko General Hospital (Athens, Greece).

Chemotherapy regimen. TIP chemotherapy was administered according to the following three- weekly schedule: Paclitaxel $\left(\right.$ Taxol $^{\circledR}$ ) was administered at $135-215 \mathrm{mg} \mathrm{m}^{-2}$ over $1 \mathrm{~h}$ by intravenous (i.v.) infusion on day 1 , following premedication consisting of dexamethasone $20 \mathrm{mg}$, dimethindene maleate $\left(\right.$ Fenistil $\left.{ }^{\circledR}\right) 4 \mathrm{mg}$ and ranitidine $50 \mathrm{mg}$; all were administered i.v. $1 \mathrm{~h}$ prior to paclitaxel. Ifosfamide was administered at 4.5-6.0 $\mathrm{g} \mathrm{m}^{-2}$ i.v. over $1 \mathrm{~h}$ divided between days 1 and 2 (2.25-3.0 $\mathrm{g} \mathrm{m}^{-2}$ per day) along with mesna uroprotection, $40 \%$ of the ifosfamide dose, administered i.v. before and at 3 and $6 \mathrm{~h}$ after ifosfamide. Cisplatin $80-100 \mathrm{mg} \mathrm{m}^{-2}$ was administered i.v. over 30 min divided between days 1 and 2 (40-50 $\mathrm{mg} \mathrm{m}^{-2}$ per day), with adequate vigorous pre- and post-hydration, furosemide and electrolyte replacement (20 $\mathrm{mEq}$ potassium chloride and $8 \mathrm{mEq}$ magnesium sulphate per litre of post-hydration solution). For febrile neutropenia, primary prophylaxis (filgrastim $5 \mathrm{mg} / \mathrm{kg}$ ) was administered until recovery of neutrophils. Dose modifications for all three chemotherapeutic drugs were made in patients with chemotherapy-related toxicities. All the toxicities were graded according to the Common Toxicity Criteria for
Table I. Patient characteristics and clinical parameters.

\begin{tabular}{lcc}
\hline Characteristics & $\begin{array}{c}\text { Group A } \\
\text { (responders) } \\
\text { no. }(\%)\end{array}$ & $\begin{array}{c}\text { Group B } \\
\text { (non-responders), } \\
\text { no. }(\%)\end{array}$ \\
\hline Total patients & $35(100)$ & $35(100)$ \\
Gender & & \\
Male & $30(87)$ & $26(74)$ \\
Female & $5(13)$ & $9(26)$ \\
Age (years) & 58 & 56 \\
Median & $40-72$ & $48-70$ \\
Range & & $11(32)$ \\
Performance status & $13(37)$ & $24(68)$ \\
0 & $22(63)$ & $20(57)$ \\
1 & & $13(37)$ \\
Histology & $20(57)$ & $2(6)$ \\
Adenocarcinoma & $11(32)$ & \\
Squamous cell Ca & $4(11)$ & \\
Large-cell Ca & &
\end{tabular}

Table II. Descriptive table depicting the results of immunostaining scores of each examined parameter in 70 patients with non-small-cell lung cancer.

\begin{tabular}{lccc}
\hline Parameters & Mean & Median & SEM \\
\hline VEGFR-1 & 7.83 & 5.0 & 0.87 \\
VEGFR-2 & 5.56 & 5.0 & 0.79 \\
VEGFR-3 & 15.86 & 15.0 & 1.49 \\
CD34 & 16.29 & 15.0 & 1.29 \\
\hline
\end{tabular}

VEGFR, vascular endothelial growth factor receptor; SEM, standard error of the mean.

Table III. Descriptive table depicting the results of immunostaining scores of the endothelial antigen CD105 in 70 patients with non-small-cell lung cancer.

\begin{tabular}{|c|c|c|c|}
\hline \multirow[b]{2}{*}{ Antigen } & \multicolumn{2}{|c|}{ Response } & \multirow[b]{2}{*}{ Total } \\
\hline & NR & $\mathrm{R}$ & \\
\hline \multicolumn{4}{|l|}{ CD105 } \\
\hline \multicolumn{4}{|l|}{ Score 0} \\
\hline \multicolumn{4}{|l|}{ Score 10} \\
\hline Patient no. (\%) & $3(8.6)$ & $10(28.6)$ & $13(18.6)$ \\
\hline \multicolumn{4}{|l|}{ Total } \\
\hline Patient no. (\%) & $35(100.0)$ & $35(100.0)$ & $70(100.0)$ \\
\hline $\begin{array}{l}81.4 \% \text { of the patient } \\
\text { who exhibited immu } \\
\text { significant difference } \\
\text { responders }(\mathrm{R}) \text { and } \\
\text { were considered stat }\end{array}$ & $\begin{array}{l}\text { did not expres } \\
\text { staining for th } \\
\text { the distributi } \\
\text { n-responders } \\
\text { cally significa }\end{array}$ & $\begin{array}{l}\text { he CD105 ant } \\
\text { CD105 marke } \\
\text { of CD105 ex } \\
\text { R) }(\mathrm{P}=0.06) .\end{array}$ & $\begin{array}{l}\text { en vs. } 18.6 \% \\
\text { There was no } \\
\text { ession among } \\
\text { values }<0.05\end{array}$ \\
\hline
\end{tabular}


Table IV. Descriptive table depicting the results of immunostaining scores of each examined parameter in the responder and non-responder groups of non-small-cell lung cancer patients.

\begin{tabular}{|c|c|c|c|c|c|c|}
\hline Parameters & Response & $\mathrm{N}$ & Mean & SD & SEM & P-value \\
\hline \multirow[t]{2}{*}{ VEGFR-1 } & NR & 35 & 4.29 & 3.862 & 0.653 & \multirow[t]{2}{*}{$<0.001$} \\
\hline & $\mathrm{R}$ & 35 & 11.37 & 8.153 & 1.378 & \\
\hline \multirow[t]{2}{*}{ VEGFR-2 } & NR & 35 & 6.00 & 4.505 & 0.761 & \multirow[t]{2}{*}{0.06} \\
\hline & $\mathrm{R}$ & 35 & 5.11 & 8.231 & 1.391 & \\
\hline \multirow[t]{2}{*}{ VEGFR-3 } & NR & 35 & 7.29 & 4.902 & 0.829 & \multirow[t]{2}{*}{$<0.001$} \\
\hline & $\mathrm{R}$ & 35 & 24.43 & 11.805 & 1.995 & \\
\hline \multirow[t]{2}{*}{ CD34 } & NR & 35 & 10.00 & 5.557 & 0.939 & \multirow[t]{2}{*}{$<0.001$} \\
\hline & $\mathrm{R}$ & 35 & 22.57 & 11.073 & 1.872 & \\
\hline
\end{tabular}

SD, standard deviation; SEM, standard error of the mean; VEGFR, vascular endothelial growth factor receptor; R, responders; NR, non-responders. P-values $<0.05$ were considered statistically significant.

Adverse Events (30). The patients received up to 4 cycles of chemotherapy and evaluation of response was performed every 2 cycles by X-rays, computed tomography (CT) scans and bone scans using the Response Evaluation Criteria in Solid Tumours, version 1.0 (31). Patients showing complete or partial response on induction chemotherapy were classified as responders and were subsequently offered either lobectomy or pneumonectomy, with resection of the involved lymph node stations. Non-responders received $\leq 6$ cycles of TIP and were offered radical radiotherapy.

Immunocytochemistry. Tumour samples were obtained at the time of diagnosis via bronchoscopy. The tumour specimens were initially fixed in $10 \%$ neutral buffered formaldehyde and then embedded in paraffin wax. Sections $(4 \mu \mathrm{m})$ were cut consecutively. Immunohistochemistry was performed on the most representative areas of viable tumour cells, avoiding areas of extensive necrosis or haemorrhage at the Pathology Department of the National and Kapodistrian University of Athens.

The antibodies used were Monoclonal rabbit VEGFR-1/Flt1 (dilution 1:50-1:100; cat. no. RP 077), policlonal rabbit VEGFR-2/Flk1 (dilution 1:50-1:100; cat. no. RP 07), policlonal rabbit VEGFR-3/Flt4 (dilution 1:50-1:10; cat. no. RP135) (all from Diagnostic BioSystems, CA, USA), rabbit recombinant monoclonal CD-105 (dilution 1:5-1:10; cat. no. M3527) and monoclonal mouse CD-34 (Class II Clone QBEnd-10; cat. no. GA632) (both from Dako, Glostrup, Denmark).

The results were recorded by two experienced pathologists by independently counting the percentage of positive cells and the intensity of staining in each section $(1+$, mild; $2+$, moderate; and $3+$, intense). The immunostaining scores were calculated by multiplying the percentage of labeled cells by the intensity of staining. MVD was evaluated on immunostained sections with CD34 and CD105 and it was determined in the three areas of maximal vascularization by using the criteria of Weidner et al (32).

The specificity of the immunohistochemical procedures was verified by using negative and positive control sections. The negative controls for each tissue were prepared by omitting the primary antibody. Sections from human placenta and tonsils were used as positive controls.

Statistical analysis. Descriptive statistics were used to present the main statistical measures of the parameters under investigation. The statistical measures used were frequencies and percentages for the discrete variables, and descriptive statistics [mean, median, standard error of the mean (SEM) and range] for the continuous parameters. In cases where the normal distribution assumption was rejected via the Kolmogorov-Smirnov test, the Mann-Whitney test was implemented to compare the marker distribution between the two patient groups. The Chi-square test was also used to test the association between two discrete variables. Survival rates were estimated with the Kaplan-Meier product limit method and compared with the log-rank test. All analyses were implemented at a significance level of $\alpha=5 \%$ with the use of the SPSS v16.0 software (SPSS Inc., Chicago, IL, USA).

\section{Results}

Analysis of immunostaining scores of angiogenic factors in NSCLC. The tumour samples from 70 NSCLC patients exhibited an overall mean immunostaining score of $7.83(\mathrm{SEM}=0.87)$ for the angiogenic factor VEGFR-1, $5.56(\mathrm{SEM}=0.79)$ for VEGFR-2 and $15.86(\mathrm{SEM}=1.49)$ for VEGFR-3. The overall mean value of the endothelial antigen CD34 was 16.29 (SEM=1.29). Table II describes the overall mean, median and SEM values of the immunostaining scores of the lung tissue expression of VEGFR-1, VEGFR-2, VEGFR-3 and the endothelial marker CD34.

The expression of the angiogenic marker CD105 exhibited a multivariate distribution. In total, $81.4 \%$ of the patients did not express the CD105 antigen on the endothelial cells of tumour tissue, whereas $18.6 \%$ exhibited immunostaining for the same endothelial marker (Table III).

Variability in expression patterns of angiogenic factors between responders and non-responders. Table IV describes the mean value, standard deviation and SEM value of the immunostaining 


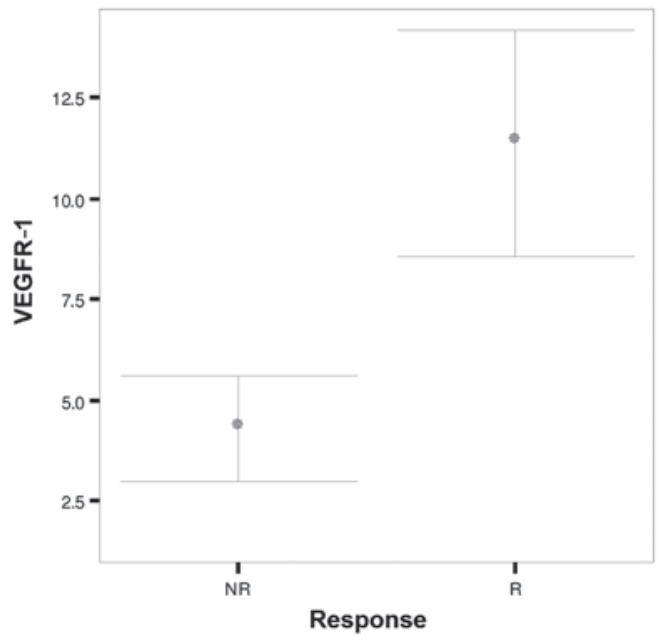

Figure 1. Schematic representation and comparison of the levels of tissue vascular endothelial growth factor receptor-1 (VEGFR-1) expression between responders (R) and non-responders (NR). Error bars, $95 \%$ confidence interval of the mean.

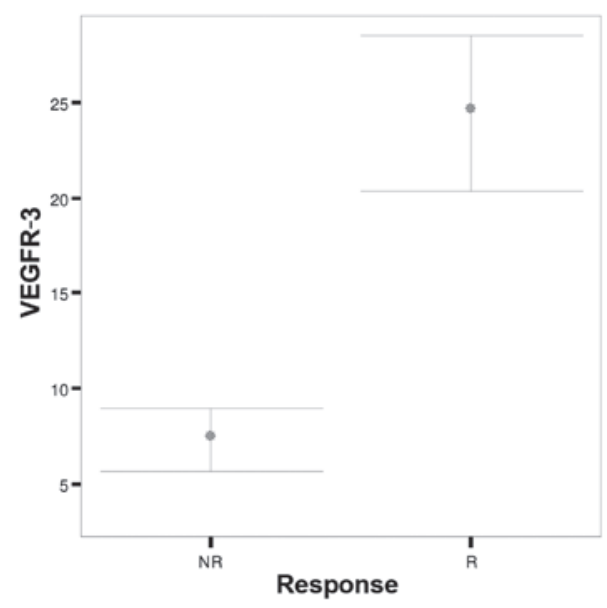

Figure 2. Schematic representation and comparison of the levels of tissue vascular endothelial growth factor receptor-3 (VEGFR-3) expression between responders (R) and non-responders (NR). Error bars, 95\% confidence interval of the mean.

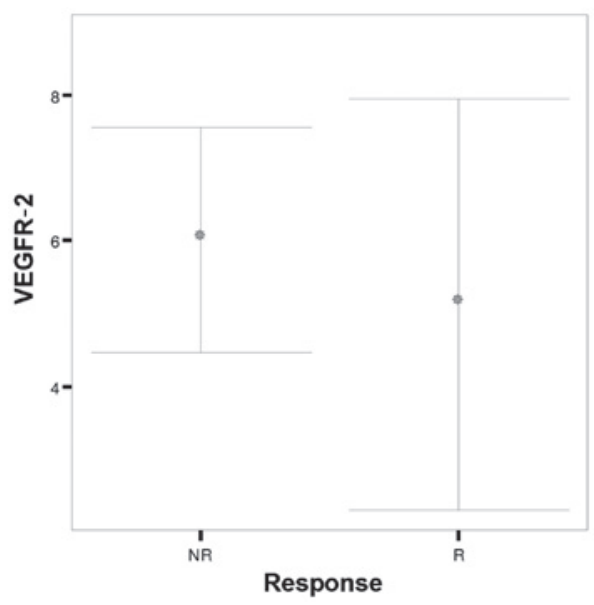

Figure 3. Schematic representation and comparison of the levels of tissue vascular endothelial growth factor receptor-2 (VEGFR-2) expression between responders (R) and non-responders (NR). Error bars, $95 \%$ confidence interval of the mean.

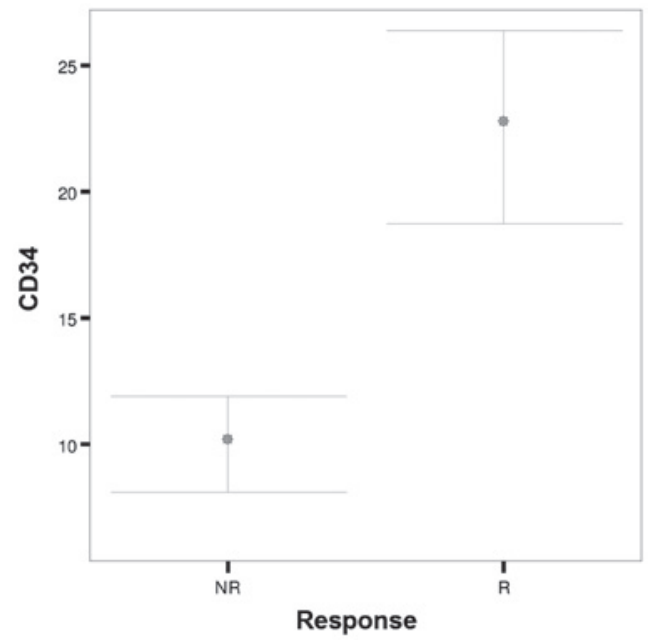

Figure 4. Schematic representation and comparison of the levels of endothelial CD34 expression between responders (R) and non-responders (NR). Error bars, $95 \%$ confidence interval of the mean.

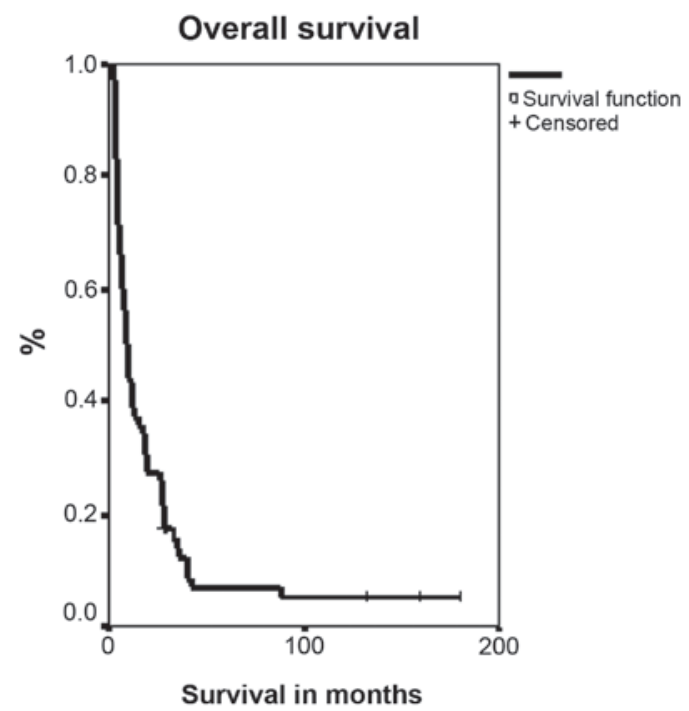

Figure 5. Median overall survival.

scores of VEGFR-1, VEGFR-2, VEGFR-3 and CD34 between responders and non-responders to chemotherapy.

Patients who responded to chemotherapy had significantly higher pre-treatment immunostaining scores for VEGFR-1 and VEGFR-3 compared with non-responders $(\mathrm{P}<0.001)$ (Figs. 1 and 2). No significant difference was noted in VEGFR-2 ( $\mathrm{P}=0.06)$ immunostaining scores between the two patient groups (Fig. 3). The CD34 immunostaining score was significantly higher in those who responded compared with those who did not respond to treatment $(\mathrm{P}<0.001)$ (Fig. 4). There was no significant difference in the distribution of the CD105 expression between responders and non-responders $(\mathrm{P}=0.06)$ (Table III). The median survival for the 70 patients was 8.5 months (Fig. 5).

\section{Discussion}

Angiogenesis is one of hallmarks of cancer evolution, as laid out by Hanahan and Weinberg (1). VEGFRs play a significant 
biological role in this process; however, there is no solid evidence regarding the prognostic effect of VEGFR expression on disease outcome.

A number of earlier studies have assessed the prognostic significance of VEGFRs in NSCLC, with controversial findings $(14,15)$. Particularly, in a meta-analysis, the VEGF expression was found to be associated with dismal outcome in patients with NSCLC (16). In line with this finding were the results of another study, which demonstrated a significant association of strong VEGFR-1 and VEGFR-2 expression with worse survival, whereas the expression of VEGFR-3 was associated with a favorable outcome in the study population (4).

In a recent meta-analysis of 5,386 NSCLC and SCLC patients, VEGF overexpression indicated poor survival for those with NSCLC histology, whereas VEGFR-3 expression did not affect prognosis (17).

Although the majority of these studies identified a correlation between VEGFR-1 and VEGFR-2 expression with poor prognosis, the data regarding the association of VEGFR3 expression with survival are conflicting. For example, in a study of 180 NSCLC patients, the cases who stained positive for VEGF-C and VEGFR-3 exhibited worse survival rates compared with those with weak to no staining $(\mathrm{P}=0.003$ and 0.001 respectively) (18).

The diversity of the patient cohorts in terms of stage, histology, median follow-up and size between the various studies may, to some extent, account for these disparities.

Interestingly, in a previous study, angiogenic factor expression was strongly correlated with lower risk of progression only for patients with early-stage squamous cell lung cancer, but not for those with adenocarcinoma, which underlined the diverse biological role of angiogenesis between different histological subtypes of NSCLC (19).

Several studies have assessed an eventual association between MVD and prognosis in NSCLC patient. Macchiarini et al (20) demonstrated that an increased MVD count predicted the aggressive behaviour of the disease. In particular, NSCLC cases with increased MVD exhibited a higher metastatic potential, tumour size and proliferative activity. A meta-analysis published by Meert et al concluded that a high MVD assessed by CD34, factor VIII and CD31, is a poor prognostic factor of survival for surgically treated NSCLC patients (13).

However, in a meta-analysis of 2,719 NSCLC patients, MVD was not proven to be a prognostic marker of survival (33). It was therefore suggested that the apparent inconsistency may be attributed to methodological differences between studies, such as the antibody/marker used, sample selection and counting methods.

Regarding NSCLC management, induction chemotherapy, with or without the addition of radiotherapy, has been considered the gold standard treatment for stage IIIA NSCLC (34). However, in the currently available literature, no angiogenesis-related predictive factors of response to chemotherapy have been validated in large studies in this setting.

In the BATTLE trial (21), 255 heavily pretreated NSCLC patients were randomly allocated to receive erlotinib, vandetanib, erlotinib plus bexarotene, or sorafenib, based on molecular biomarkers assessed in fresh core needle biopsy specimens. Patients with high tumour VEGFR-2 expression exhibited improved 8-week disease control rates following treatment with vandetanib, compared with those exhibiting low VEGFR-2 expression $(\mathrm{P}=0.05)$. However, despite the improved control rate, VEGFR-2 expression failed to confer any statistically significant overall survival benefit in this phase II study.

Interestingly, several immunocytochemical markers, including angiogenesis markers, were evaluated in 515 cases of stage I NSCLC in relation to the clinical course of the disease. No sufficient evidence supporting any change in clinical practice emerged from that study (22).

Surprisingly, in a previous study, a high MVD index was predictive of disease response in NSCLC patients who received chemotherapy with the addition of bevacizumab, a monoclonal anti-VEGF antibody (23). In particular, a strong correlation was observed between the largest percentage of tumour shrinkage and the MVD of undifferentiated vessels $(\mathrm{P}=0.019)$. However, this finding has yet to be validated in large studies.

In a recently published study, the predictive value of several angiogenic biomarkers, including angiopoietin-2, bone morphogenetic protein-9, epidermal growth factor (EGF), endoglin, endothelin-1, fibroblast growth factor (FGF)-1, FGF-2, follistatin, granulocyte-colony stimulating factor, heparin-binding EGF, hepatocyte growth factor (HGF), interleukin-8, leptin, placental growth factor, VEGF-A, VEGF-C, and VEGF-D, was assessed in 41 patients with stage IV non-squamous NSCLC, treated with either chemotherapy alone or with the addition of bevacizumab. Serum was collected before and after treatment initiation. An increased VEGF-A level after the first cycle of chemotherapy was correlated with worse progression-free survival (PFS) in patients who received chemotherapy with bevacizumab. By contrast, increased leptin levels were associated with improved survival in the group that received the antibody. Increased angiopoietin-2, HGF, follistatin, VEGF-C and VEGF-D levels were associated with poor survival, whereas increased FGF-1 and endothelin-1 levels predicted improved survival (25). Another study evaluated the same panel of angiogenic factors in 68 patients with stage IV non-squamous NSCLC, treated with either chemotherapy alone or with the addition of bevacizumab. Serum was collected immediately prior to chemotherapy. High levels of endothelin-1, follistatin and VEGF-C were associated with worse PFS, regardless of the type of chemotherapy. High HGF levels conferred worse PFS and overall survival in patients who received chemotherapy with bevacizumab compared with those who received chemotherapy alone. Similarly, high endoglin levels were correlated with worse PFS in patients who received the antibody (24).

In our study, the expression of certain angiogenic factors in relation to the response to induction TIP chemotherapy was retrospectively assessed. The unexpectedly high response rate (64\%; 95\% confidence interval: 50.7-77.3\%) observed with this regimen in a previous study by our group led us to retrospectively focus on possible biomarkers affecting prognosis and chemotherapy effectiveness in the study population (27).

Although there is no direct evidence that TIP chemotherapy or its individual components target angiogenesis, the association between high pretreatment expression of VEGFR-1 and VEGFR-3 and the response to chemotherapy 
in our study may advocate a possible connection. In support of this hypothesis, data presented by Linderholm et al demonstrated that a decrease of circulating VEGF level affects time-to-progression after 12 weeks of therapy with weekly paclitaxel in metastatic breast cancer patients, supporting a possible role for angiogenic factors in monitoring the treatment efficacy of non-VEGF-targeted therapies (35).

Furthermore, there is strong evidence of crosstalk between several diverse molecular pathways driving tumour invasion and metastasis in the cancer cell and its microenvironment (36). For example, agents targeting certain gene aberrations may also induce antiangiogenic responses. This may occur due to the downregulation of proangiogenic factors (37).

We therefore hypothesized there may be crosstalk between angiogenesis and molecular events that repair DNA damage, such as nucleotide excision repair and base-mismatch repair pathways. This hypothesis may explain the high effectiveness of the TIP regimen, which inhibits the repair of DNA lesions, in the presence of a high expression of VEGFR-1, VEGFR-3 and CD34.

Tumour stroma, which is composed of fibroblastic, inflammatory and immune cells, is an additional source of angiogenic factors (38). In particular, there is a network of paracrine and autocrine signaling pathways within the tumour cell and its microenvironment. This network may be an appealing therapeutic target in NSCLC (39). Tumour-inducible hypoxia in the stroma may impede the activity of common chemotherapy regimens. The synergism between paclitaxel and alkylating agents, such as cisplatin and ifosfamide, has been extensively investigated (40). This phenomenon may explain the effectiveness of the TIP regimen as an induction or even rescue treatment in several diverse malignancies (41-43). Whether the TIP regimen may overcome the tumour hypoxia and exert its action in the tumour microenvironment requires further investigation.

In our study, CD34 expression was evident in all the samples examined and significantly higher in responders, whereas only one-fifth of the patients exhibited immunostaining for the marker CD105, without any effect on treatment outcome. A likely reason for this variability is the inherent capacity of the pan-endothelial marker CD34 to react well with endothelial cells in all blood vessels (11), as opposed to CD105, which appears to bind preferentially to activated endothelial cells in tissues participating in angiogenesis (12).

The retrospective nature and the small population of our study limit the impact of the results. However, given the scarcity of the literature in translational research studies and the lack of predictive factors in the treatment of non-metastatic NSCLC, we suggest that the results of this study merit further investigation. In line with this, we plan to conduct a study in order to assess angiogenic factor expression and its effect on response to chemotherapy regimens with antiangiogenic activity, such as bevacizumab and metronomic vinorelbine, for stage IV NSCLC patients.

\section{References}

1. Hanahan D and Weinberg RA: Hallmarks of cancer: The next generation. Cell 144: 646-674, 2011.

2. Benelli R, Lorusso G, Albini A and Noonan DM: Cytokines and chemokines as regulators of angiogenesis in health and disease. Curr Pharm Des 12: 3101-3115, 2006.
3. Bremnes RM, Camps C and Sirera R: Angiogenesis in non-small cell lung cancer: The prognostic impact of neoangiogenesis and the cytokines VEGF and bFGF in tumours and blood. Lung Cancer 51: 143-158, 2006

4. Carrillo de Santa Pau E, Arias FC, Caso Peláez E, Muñoz Molina GM, Sánchez Hernández I, Muguruza Trueba I, Moreno Balsalobre R, Sacristán López S, Gómez Pinillos A and del Val Toledo Lobo M: Prognostic significance of the expression of vascular endothelial growth factors A, B, C and D and their receptors R1, R2 and R3 in patients with nonsmall cell lung cancer. Cancer 115: 1701-1712, 2009.

5. Cébe-Suarez S, Zehnder-Fjällman A and Ballmer-Hofer K: The role of VEGF receptors in angiogenesis; complex partnerships. Cell Mol Life Sci 63: 601-615, 2006.

6. Rapisarda A and Melillo G: Role of the VEGF/VEGFR axis in cancer biology and therapy. Adv Cancer Res 114: 237-267, 2012.

7. Smith NR, Baker D, James NH, Ratcliffe K, Jenkins M, Ashton SE, Sproat G, Swann R, Gray N, Ryan A, et al: Vascular endothelial growth factor receptors VEGFR-2 and VEGFR-3 are localized primarily to the vasculature in human primary solid cancers. Clin Cancer Res 16: 3548-3561, 2010.

8. Hiratsuka S, Nakamura K, Iwai S, Murakami M, Itoh T, Kijima H, Shipley JM, Senior RM and Shibuya M: MMP9 induction by vascular endothelial growth factor receptor-1 is involved in lung-specific metastasis. Cancer Cell 2: 289-300, 2002.

9. Lenton K: VEGFR-2 (KDR/Flk-1). J Biol Regul Homeost Agents 16: 227-232, 2002.

10. Shibuya M and Claesson-Welsh L: Signal transduction by VEGF receptors in regulation of angiogenesis and lymphangiogenesis. Exp Cell Res 312: 549-560, 2006.

11. Fontanini G, Bigini D, Vignati S, Basolo F, Mussi A, Lucchi M, Chine S, Angeletti CA, Harris AL and Bevilacqua G: Microvessel count predicts metastatic disease and survival in non-small cell lung cancer. J Pathol 177: 57-63, 1995.

12. Kumar P, Wang JM and Bernabeu C: CD 105 and angiogenesis. J Pathol 178: 363-366, 1996.

13. Meert AP, Paesmans M, Martin B, Delmotte P, Berghmans T, Verdebout JM, Lafitte JJ, Mascaux C and Sculier JP: The role of microvessel density on the survival of patients with lung cancer: A systematic review of the literature with meta-analysis. Br J Cancer 87: 694-701, 2002.

14. Volm M, Koomägi R and Mattern J: Prognostic value of vascular endothelial growth factor and its receptor Flt-1 in squamous cell lung cancer. Int J Cancer 74: 64-68, 1997.

15. Decaussin M, Sartelet H, Robert C, Moro D, Claraz C, Brambilla $\mathrm{C}$ and Brambilla E: Expression of vascular endothelial growth factor (VEGF) and its two receptors (VEGF-R1-Flt1 and VEGF-R2-Flk1/KDR) in non-small cell lung carcinomas (NSCLCs): Correlation with angiogenesis and survival. J Pathol 188: 369-377, 1999.

16. Delmotte P, Martin B, Paesmans M, Berghmans T, Mascaux C, Meert AP, Steels E, Verdebout JM, Lafitte JJ and Sculier JP: VEGF and survival of patients with lung cancer: A systematic literature review and meta-analysis. Rev Mal Respir 19: 577-584, 2002 (In French).

17. Zhan P, Wang J, Lv XJ, Wang Q, Qiu LX, Lin XQ, Yu LK and Song Y: Prognostic value of vascular endothelial growth factor expression in patients with lung cancer: A systematic review with meta-analysis. J Thorac Oncol 4: 1094-1103, 2009.

18. Arinaga M, Noguchi T, Takeno S, Chujo M, Miura T and Uchida Y: Clinical significance of vascular endothelial growth factor $\mathrm{C}$ and vascular endothelial growth factor receptor 3 in patients with nonsmall cell lung carcinoma. Cancer 97: 457-464, 2003.

19. Pajares MJ, Agorreta J, Larrayoz M, Vesin A, Ezponda T, Zudaire I, Torre W, Lozano MD, Brambilla E, Brambilla C, et al: Expression of tumor-derived vascular endothelial growth factor and its receptors is associated with outcome in early squamous cell carcinoma of the lung. J Clin Oncol 30: 1129-1136, 2012.

20. Macchiarini P, Fontanini G, Hardin MJ, Squartini F and Angeletti CA: Relation of neovascularisation to metastasis of non-small-cell lung cancer. Lancet 340: 145-146, 1992.

21. Kim ES, Herbst RS, Wistuba II, Lee JJ, Blumenschein GR Jr, Tsao A, Stewart DJ, Hicks ME, Erasmus J Jr, Gupta S, et al: The BATTLE trial: Personalizing therapy for lung cancer. Cancer Discov 1: 44-53, 2011.

22. Pastorino U, Andreola S, Tagliabue E, Pezzella F, Incarbone M, Sozzi G, Buyse M, Menard S, Pierotti M and Rilke F: Immunocytochemical markers in stage I lung cancer: Relevance to prognosis. J Clin Oncol 15: 2858-2865, 1997. 
23. Zhao YY, Xue C, Jiang W, Zhao HY, Huang Y, Feenstra K, Resau JH, Qian CN and Zhang L: Predictive value of intratumoral microvascular density in patients with advanced non-small cell lung cancer receiving chemotherapy plus bevacizumab. J Thorac Oncol 7: 71-75, 2012.

24. Borgia JA, Pithadia R, Ibrahem Z, Fhied C, Basu S, Lie WR, Fidler MJ, Batus M and Bonomi PD: Potential predictive value of hepatocyte growth factor (HGF) in advanced non-small cell lung cancer (NSCLC) treated with a platinum doublet and bevacizumab. J Clin Oncol 32 (Suppl): e22000, 2014.

25. Batus M, Pithadia R, Kubasiak J, Fhied C, Ibrahem Z, Melinamani S, Fughhi I, Lie WR, Basu S, Fidler MJ, Bonomi PD and Borgia JA: Differences in circulating angiogenic biomarkers as prognosticator for outcome in bevacizumab-treated nonsquamous non-small cell lung cancer (NSCLC) patients. J Clin Oncol 32: (5s Suppl): S11037, 2014.

26. Pohl G, Krajnik G, Malayeri R, Müller RM, Klepetko W, Eckersberger F, Schafer-Prokop C, Pokrajac B, Schmeikal S, Maier A, et al: Induction chemotherapy with the TIP regimen (paclitaxel/ifosfamide/cisplatin) in stage III non-small cell lung cancer. Lung Cancer 54: 63-67, 2006.

27. Kosmas C, Tsavaris NB, Polyzos A, Kalofonos HP, Sepsas E, Malamos NA, Vadiaka M, Dosios T and Antonopoulos MJ: A phase II study of paclitaxel-ifosfamide-cisplatin combination in advanced nonsmall cell lung carcinoma. Cancer 89: 774-782, 2000.

28. Ripley RT and Rusch VW: Role of induction therapy: Surgical resection of non-small cell lung cancer after induction therapy. Thorac Surg Clin 23: 273-285, 2013.

29. Greene FL, Page DC, Fleming ID, et al: AJCC Cancer staging manual. 6th edition. Springer-Verlag, New York, p435, 2002.

30. Common Terminology Criteria for Adverse Events (CTCAE). Version 4.0, 2009. http://evs.nci.nih.gov/ftpl/CTCAE/CTCAE 4.03_2010-06-14_QuickReference_8.5x11.pdf. Accessed May $28,2009$.

31. Therasse P, Arbuck SG, Eisenhauer EA, Wanders J, Kaplan RS, Rubinstein L, Verweij J, Van Glabbeke M, van Oosterom AT, Christian MC, and Gwyther SG: New guidelines to evaluate the response to treatment in solid tumors. European Organization for Research and Treatment of Cancer, National Cancer Institute of the United States, National Cancer Institute of Canada. J Natl Cancer Inst 92: 205-216, 2000.

32. Weidner N, Semple JP, Welch WR and Folkman J: Tumor angiogenesis and metastasis-correlation in invasive breast carcinoma. N Engl J Med 324: 1-8, 1991.

33. Trivella M, Pezzella F, Pastorino U, Harris AL and Altman DG Prognosis In Lung Cancer (PILC) Collaborative Study Group: Microvessel density as a prognostic factor in non-small-cell lung carcinoma: A meta-analysis of individual patient data. Lancet Oncol 8: 488-499, 2007.
34. Horita N, Miyazawa N, Morita S, Kojima R, Kimura N, Kaneko T and Ishigatsubo Y: Preoperative chemotherapy is effective for stage III resectable non-small-cell lung cancer: Metaanalysis of 16 trials. Clin Lung Cancer 14: 488-494, 2013.

35. Linderholm BK, Lidbrink E, Tallroth E, Einbeigi Z, Svensson H, von Wachenfeldt A, Norberg B, Carlsson L, Olsson ME, Bergh J, et al: Angiogenic factors in relation to clinical effect in a phase II trial of weekly paclitaxel. Breast 22: 1142-1147, 2013.

36. Ma $\mathbf{J}$ and Waxman DJ: Combination of antiangiogenesis with chemotherapy for more effective cancer treatment. Mol Cancer Ther 7: 3670-3684, 2008.

37. Amin DN, Hida K, Bielenberg DR and Klagsbrun M: Tumor endothelial cells express epidermal growth factor receptor (EGFR) but not ErbB3 and are responsive to EGF and to EGFR kinase inhibitors. Cancer Res 66: 2173-2180, 2006.

38. Ferrara $\mathrm{N}$ and Kerbel RS: Angiogenesis as a therapeutic target. Nature 438: 967-974, 2005.

39. Crinò L and Metro G: Therapeutic options targeting angiogenesis in nonsmall cell lung cancer. Eur Respir Rev 23: 79-91, 2014.

40. Chou TC, Motzer RJ, Tong Y and Bosl GJ: Computerized quantitation of synergism and antagonism of taxol, topotecan and cisplatin against human teratocarcinoma cell growth: A rational approach to clinical protocol design. J Natl Cancer Inst 86: 1517-1524, 1994

41. Kondagunta GV, Bacik J, Donadio A, Bajorin D, Marion S, Sheinfeld J, Bosl GJ and Motzer RJ: Combination of paclitaxel, ifosfamide and cisplatin is an effective second-line therapy for patients with relapsed testicular germ cell tumors. J Clin Oncol 23: 6549-6555, 2005.

42. Lissoni AA, Colombo N, Pellegrino A, Parma G, Zola P Katsaros D, Chiari S, Buda A, Landoni F, Peiretti M, et al: A phase II, randomized trial of neo-adjuvant chemotherapy comparing a three-drug combination of paclitaxel, ifosfamide and cisplatin (TIP) versus paclitaxel and cisplatin (TP) followed by radical surgery in patients with locally advanced squamous cell cervical carcinoma: The Snap-02 Italian Collaborative Study. Ann Oncol 20: 660-665, 2009.

43. Mountzios G, Dimopoulos MA, Bamias A, Vourli G, Kalofonos H, Aravantinos G, Fountzilas G and Papadimitriou CA: Randomized multicenter phase II trial of cisplatin and ifosfamide with or without paclitaxel in recurrent or metastatic carcinoma of the uterine cervix: A Hellenic Cooperative Oncology Group (HeCOG) study. Ann Oncol 20: 1362-1368, 2009. 